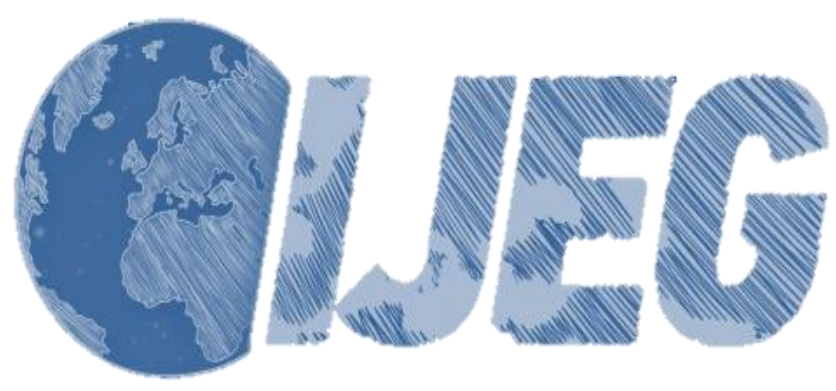

International Journal of Engineering and Geosciences (IJEG),

Vol; 4, Issue; 3, pp. 141-148, October, 2019, ISSN 2548-0960, Turkey,

DOI: 10.26833 ijeg. 540180

\title{
COMPLEXITY MEASURES OF SPORTS FACILITIES ALLOCATION IN URBAN AREA BY METRIC ENTROPY AND PUBLIC DEMAND COMPATIBILITY
}

\author{
Serdar Bilgi ${ }^{1 *}$, Ayse Giz Gulnerman ${ }^{1}$, Birgul Arslanoglu², Himmet Karaman ${ }^{1}$, Ozge Ozturk ${ }^{3}$ \\ ${ }^{1}$ Istanbul Technical University, Civil Engineering Faculty, Department of Geomatics Engineering, Istanbul, Turkey \\ (bilgi/gulnerman/karamanhi@itu.edu.tr); ORCID 0000-0002-8396-3202, ORCID 0000-0002-9163-6068, \\ ORCID 0000-0003-0507-6920, \\ ${ }^{2}$ Istanbul Technical University, Department of Physical Education, Istanbul, Turkey \\ (demirkolb@itu.edu.tr); ORCID 0000-0003-4923-3561,
}

${ }^{3}$ Yildiz Technical University, Civil Engineering Faculty, Department of Geomatics Engineering, Istanbul, Turkey (ozgeo@ yildiz.edu.tr); ORCID 0000-0002-9017-9651

*Corresponding Author, Received: 14/03/2019, Accepted: 28/06/2019

\begin{abstract}
Sports has an important role for the health of present societies and the next generations as an element of urban design. Sports facilities have strong effects on the social life in urban areas. The facilities supply the communication between the dynamics of the cities and generate synergy in the city life of people interacting with each other for improvement in their lives. Before the construction of the sports facilities, the planners must evaluate the type and size of them in terms of the population of the whole city and, the population of neighboring settlement areas, which use the facility. Entropy can be used as a criterion for the quantitative measure of spatial information on maps. In the study, the location of the sports facilities in Istanbul are compared by using the entropy as a quantitative criterion. As a result, the success of the location selection for the sports facilities in urban areas are estimated by using the entropy as a component. Metric entropy method and applications were carried out by a case study in the city of Istanbul for defining the spatial distribution of sports facility locations with the posts of people including "sports" and sports-related keywords on social media.
\end{abstract}

Keywords: Metric entropy, Urban complexity and spatial distribution, Social media data, Volunteered geographic information (VGI) 


\section{INTRODUCTION}

In the "The Culture of the Cities" by Lewis Mumford, the city is defined as; the space where diverse behaviors and expectations on the perspectives of life infiltrate into the same point, with advantages of both social efficacy and relevance as well as where personal practice reformed with symbols, terms of conducts and legal regulations (Mumford, 1938). Adams (1935), states city and town planning as "a science, an art, and a movement of policy concerned with the shaping and guiding of the physical growth and arrangement of towns in harmony with their social and economic needs'.

Cities with a population over 10 million are generally called as megacities. According to the United Nations (UN) data, there were 45 cities with populations between 5 and 10 million and 31 megacities worldwide in 2016. In the UN report, the number of megacities is extrapolated to increase up to 41 until 2030 . Whereas $23 \%$ of all population of the world lived in urban areas in 2016, extrapolated results indicate that $27 \%$ of global population will center in cities with at least 1 million population (United Nations, 2016).

Urban areas should be designed aesthetically, sustainably, interactively and sufficiently to advance the public life standards. The rapid growth of the urban population increases the pressure on human life, living in the urban since this population flow has triggered the needs of housing with no previous expectation. This kind of growth has made urban areas full of buildings without planning and infrastructure. While population has grown in the urban areas, public life standards and health have been an outstanding issue in local, national and global levels. People living in the city tend to get away from the city and integrate with nature as they find the opportunity to keep away from stress in terms of current living conditions and their effects (Kuşçu et al., 2018). However, sports facilities have substantial positive impacts on the social life of public in urban areas, supplying the communication, in addition to generating synergy in the city life by establishing better, healthier community in which people are socializing with each other. Technological developments increase every day. Especially communication technologies have developed extraordinarily for last 30 years and still developing making it easy to access worldwide information and sources of information (Iscan and Ilgaz, 2017).

Land-use is one of the essential issues in the human impact on the environment. Land-use planning is the design of valuation assets over potentials of land and water, the considerations of replacements in order to choose and implement socioeconomically best options (Food and Agriculture Organization of the UN, 2016). The function of land-use planning by assessing and overviewing all potentials is to ensure supplying the needs of public and preserving resources for future (De Wrachien, 2003). Elements of urban design including "Land-use," "Community design," and "Transportation design" noticeably affect the local quality of air and water supply as well as traffic safety and physical activity. The industrial revolution fostered rapid population growth in cities thanks to a ubiquitously increasing number of manufacturing industries in the 19th century. These cities with unrestrainedly growing population required sanitary infrastructures to overcome the inextricable masses. Therefore; land-use planning management became important (Schilling, and Linton, 2005)

Planning for sports facilities involves reserving land for open space with built facilities and consideration of how such amenities will be develop (Food and Agriculture Organization of the UN, 2016). Nowadays, sports as a multiple-sided and continually changing activity has coalesced in the modern lifestyle of urban society. Since the 1950's, there is a constant growth in sports participation in many European countries. In some countries, growth has stabilized (Van Bottenburg et al., 2005). This affects urban planning by the construction of various sports facilities and open (sports) parks in many cities.

According to Chapin (2002), sports facilities have an extensive variety of favorable and adverse impacts on their neighboring areas and cities on a broader scale. Their impacts would be considered as social, physical, safety and even political, economic, legal and environmental issues. Because a simple facility with the capacity of a few hundred people with sports facilities design the social fabric part together with the town hall and buildings of religions and serve to a small local community. The categories of sports facilities in his study are comprised of several outdoor recreational areas, courses to the indoor arena, dome, and single or multipurpose amenities (Chapin, 2002).

European Commission (2007) states within the last two decades, land-use, globalization and rapid growth of urban area in undeveloped and developing countries underline the significance of sports and sports amenities. Government and social institutions highlight the positive effects of sports on health, as well as the importance of social compliance. In contemporary political discourse, sports are investigated not only regarding its economic effect but also concerning its potential for struggling with poverty, unemployment, crime, and discrimination (Collins, 2014). Besides, Campbell and Harrison (1999) declare that sports would contribute to life quality of both individuals and communities, improve health, boost social unity, encounter anti-sociality, and promote individual self-regard and self-assurance.

Sports have become necessary to prevent health problems and to maintain a healthy life. So, it is recommended to all citizens by all relevant institutions and relevant authorities. UN has seen sports as a tool for "development" and "peace." So, they support a task force to enhance the society and sports connection and in 2005 report this mission was denoted as the relation between sports and health, education, sustainable development, peace, communication, partnerships (UN Inter Agency, 2005). As in the world, the number of people doing sports in Turkey is increasing day by day. Especially the metropolitan municipalities have built many sports facilities in order to meet the demand of the people in cities. In these mega cities, sports facilities are seen as a place of socialization as well as for sports.

There are different approaches to the sports facilities within the urban areas. That is why a comprehensive literature review from the regulations of sports areas within the spatial planning codes and blueprints that have been developed by different city planning organizations embedded in the study. The codes and regulations are based on the suitability of the minimum values of the formulas or urbanization conditions. However, the critical case is to observe the consequences of the formulas and conditions on how they contribute to public 
demand.

Volunteered Geographic Information (VGI) is a way to understand public demands which are primarily and terminologically depends on Public Participation (PP) with Geographic Information Systems (Gulnerman and Karaman, 2015; Sieber, 2006). VGI is a newer terminology than the PP- Geographic Information Systems (PPGIS). In addition to the severity of empowering NGO, populist groups and rest of the organizations are based on communities, to increase the contribution of the public in defining policies is the use cases of GIS which are implied by PPGIS (Sieber, 2006). The idea behind it explained by Anderson (Anderson, 1995) with one of the urban planning approach consulted by Public Participants. Public participation has evolved in time with the technology like the invention of web 2.0 and GNSS within smartphones (Goodchild, 2007). The terminology of this participation also has evolved by this technology. Citizen science, neo-geographers, and volunteers are some of these participators [Ball, 2002; Goodchild, 2009; Tulloch, 2008).

In this study, the demand for sports facilities is tested with social media, and Twitter users' spatial data related to sports contents used as demand dataset. Social media data which become highly available can be used to make predictive models for sports events (Ristea, 2018). Twitter has been chosen for this study due to the reason that this social media platform exceeds 28 million active users in Turkey which is one-quarter of the total population of the country (Statista, 2016). As a consequence of the number of users (participators), platforms provide the excessive data source for participation projects which is supported by unconscious volunteers (Gulnerman et.al, 2016; Shekhar, 2015).

\section{MATERIALS AND METHODS}

\subsection{Metric Entropy Method and Its Relation about Sports Facility and Implementation}

Entropy, briefly defined as the measure of the indefiniteness of a system, is also the second law of thermodynamics. This measurement is explicitly connected to information content and in association with the quantification of information transfer attempts within a communication system (Fairbairn, 2006).

Maps are giving us a picture of the environment, and since the early ages, they have been used as the abstraction of the real world for thousands of years. The description of cartographic representations can be defined with the term "complexity," considering the general nature. There have been many attempts with practical testing to measure the complexity of the literature. These studies date the back the too late 1940s by Shannon (1948) and Shannon et al. (1951) which is named as information theory and was carried out to communication theory.

The first study adopting entropy to cartographic communication for quantitative measurement of map information has been done by Sukhov $(1967 ; 1970)$. Statistics of the different types of symbols used on the map taken into account. Numbers of each type of symbols are taken into consideration. Information is modeled as a probabilistic process in these studies. Entropy is computed as follows Eq. (1), assuming $\mathrm{X}$, the random message variable, $\mathrm{P}_{1}, \mathrm{P}_{2}, \ldots \mathrm{P}_{\mathrm{i}}, \ldots \mathrm{P}_{\mathrm{n}}$ are the probabilities of different message choices;

$$
H(X)=H\left(P_{1}, P_{2}, \ldots, P_{n}\right)=-\sum_{i=1}^{n} P_{i} * \ln \left(P_{i}\right)
$$

A new method for calculating the topological information of the map is suggested by Neumann (1994). The method is two-staged, classifying the vertices due to their neighboring relations and forming a dual graph, then computing the entropy. The entropy of the map is calculated as follows Eq. (2), assuming $\mathrm{N}$ : the total number of the symbols, M: number of symbol types and Ki: number of symbols for an $\mathrm{i}^{\text {th }}$ type. Then and the probability for each type of symbols is: where $\mathrm{P}_{\mathrm{i}}$ is the probability of $\mathrm{i}^{\text {th }}$ symbol type, $\mathrm{i}=1,2, \ldots \mathrm{M}$.

$H(X)=H\left(P_{1}, P_{2}, \ldots, P_{M}\right)=-\sum_{i=1}^{M} P_{i} * \ln \left(P_{i}\right)$

Later on, Bjørke (1996) questioned the usefulness of such topological information and compared maps in different scale and design, in order to evaluate the information on maps quantitatively. Metrical entropy method is introduced considering the variation of the distances between the map objects. $\mathrm{n}$ is the number of objects, $S$ is the whole area tessellated by $S_{i}$ where $S_{i}$ is the Voronoi regions of each sports facility $\left(\mathrm{i}=1,2, \ldots \mathrm{n}^{\text {th }}\right)$, $\mathrm{P}_{\mathrm{i}}$ is the probability $\left(P_{i}=\frac{s_{i}}{S}\right)$ and the entropy $\mathrm{H}(\mathrm{M})$ was defined as Eq. (3) given below:

$H(M)=H\left(P_{1}, P_{2}, \ldots, P_{n}\right)=-\sum_{i=1}^{n} \frac{S_{i}}{S} *\left(\ln S_{i}-\ln S\right)(3)$

The concept of occupied space by objects in the map is related to the metric information. As the space occupied by the objects are approximately equal on the map, the information contained on the map will increase. Otherwise, the amount of information will decrease. So, the probability can be significant for the determination of entropy by using the ratio between the Voronoi region of the map and designated part of the area (Li and Huang, 2002).

Forming the mosaics on the map will be the most suitable solution to determine the occupied spaces by the objects and these regions will contain all of the objects in the map. The most appropriate method for this solution is the Voronoi diagrams (Lee et.al, 2000).

\subsection{Voronoi Diagrams}

The earliest documented knowledge about Voronoi diagrams is dated back to two scientists who lived in the Renaissance period: Johannes Kepler (1571-1630) and Ren'e Descartes (1596-1650). Descartes used the Voronoi diagrams to confirm that the distribution of matter in the universe, forms vortices centered at fixed stars. Moreover, Voronoi and Delaunay tessellations generated by integer lattices had been introduced by Kepler. Mathematician Johann Peter Gustav Lejeune Dirichlet (1850), created some of his seminal work on quadratic forms. Following earlier ideas by Kepler and Carl Friedrich Gauss, he considered Voronoi partitions of space are caused by integer grid points as sites (Liebling, 2012). Voronoi diagrams are also called Dirichlet tessellations or Wigner-Seithz (Watson, 1994; Sukumar et.al, 2001). The Voronoi diagrams investigation is extended to a higher dimension by Voronoi's studies 
(Voronoi, 1908; 1909). A Voronoi diagram is a 2-D plane divided into the polygonal regions. Each of these regions is associated with a specific map object. The associated region with this characteristic is the locus of points closer to that object than to any other map objects ( $\mathrm{Li}$ and Huang, 2002).

\section{CASE STUDY}

The study aims to test the sports facility supply in the urban area. For this purpose, the authors assessed the distribution of sports facilities by social media data. Metric entropy method is used as a norm for the quantitative measure of spatial information on maps. This paper also evaluated the location of the sports facilities by using such a quantitative norm. This method experimented with a case study, studied in Istanbul for defining the spatial distribution of the sports facilities. First of all, the existing sports facilities were overlaid by districts of the city of Istanbul. Then, Voronoi diagrams were created for the sport facility locations and metric entropy calculations were carried out.

The third step of the case study was to determine the sport facility users' demands by using the geo-referenced social media data. As a result, the demands of the users were measured by selecting the sports facility locations in relation with the district. These measures represent the consistency between the selected locations in districts and user needs in a scientific manner.

In order to determine the public need for sports facilities, Twitter tweets with location information were used. The tweets in May 2016 in the bounding box of Istanbul is filtered through Twitter Streaming API using Java-based Geo Tweets Downloader tool and stored into PostGIS database (Gengeç, 2015).

Social media data has been accepted as the demand of society. In this study, citizens who tweeted about a kind of sports, having texts such as "football," "basketball," "fitness," "swimming," "tennis" etc. are filtered and used in the spatial analysis. Such tweets meant a relation with sports and assumed that there is demand for it. There were more than 870.475 of tweets (maximum 40.507 tweets on 15.05.2016 and minimum 22.633 tweets on 27.05.2016) during the identified time interval, and 6710 of them were determined to be related to sports. Social media data used, "number of total tweets by day" and "number of sports tweets by day" can be seen in Table 1 and Figure 1(a) and 1(b). The number of total tweets and number of the sports facility in the districts of Istanbul city are shown in Table 2.

Table 1 Number of total tweets and number of sports tweets by day.

\begin{tabular}{cccc}
\hline Date & Tweet & Date & $\begin{array}{c}\text { Sports } \\
\text { Tweets }\end{array}$ \\
\hline 01.05 .2016 & 31161 & 01.05 .2016 & 740 \\
02.05 .2016 & 26602 & 02.05 .2016 & 184 \\
03.05 .2016 & 25953 & 03.05 .2016 & 153 \\
04.05 .2016 & 26844 & 04.05 .2016 & 231 \\
05.05 .2016 & 27090 & 05.05 .2016 & 174 \\
06.05 .2016 & 29717 & 06.05 .2016 & 158 \\
07.05 .2016 & 35742 & 07.05 .2016 & 206 \\
08.05 .2016 & 35658 & 08.05 .2016 & 122 \\
09.05 .2016 & 27119 & 09.05 .2016 & 164 \\
10.05 .2016 & 25940 & 10.05 .2016 & 170
\end{tabular}

\begin{tabular}{cccc}
11.05 .2016 & 26862 & 11.05 .2016 & 156 \\
12.05 .2016 & 27136 & 12.05 .2016 & 149 \\
13.05 .2016 & 29869 & 13.05 .2016 & 159 \\
14.05 .2016 & 35182 & 14.05 .2016 & 160 \\
15.05 .2016 & 40507 & 15.05 .2016 & 640 \\
16.05 .2016 & 28575 & 16.05 .2016 & 152 \\
17.05 .2016 & 25682 & 17.05 .2016 & 159 \\
18.05 .2016 & 27752 & 18.05 .2016 & 294 \\
19.05 .2016 & 34798 & 19.05 .2016 & 457 \\
20.05 .2016 & 28735 & 20.05 .2016 & 148 \\
21.05 .2016 & 27475 & 21.05 .2016 & 109 \\
22.05 .2016 & 25588 & 22.05 .2016 & 110 \\
23.05 .2016 & 23775 & 23.05 .2016 & 140 \\
24.05 .2016 & 23875 & 24.05 .2016 & 144 \\
25.05 .2016 & 23664 & 25.05 .2016 & 364 \\
26.05 .2016 & 23109 & 26.05 .2016 & 128 \\
27.05 .2016 & 22633 & 27.05 .2016 & 371 \\
28.05 .2016 & 28578 & 28.05 .2016 & 94 \\
29.05 .2016 & 28373 & 29.05 .2016 & 92 \\
30.05 .2016 & 23473 & 30.05 .2016 & 105 \\
31.05 .2016 & 23008 & 31.05 .2016 & 125 \\
Total & $\mathbf{8 7 0 4 7 5}$ & & $\mathbf{6 5 5 8}$ \\
\hline
\end{tabular}

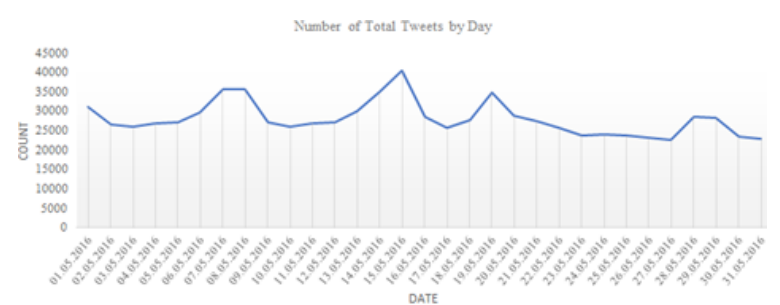

(a)

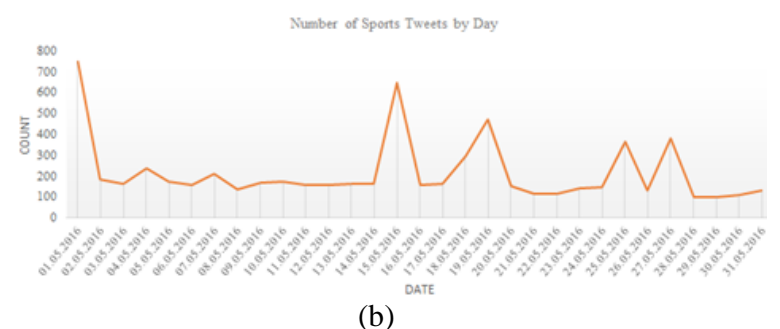

Figure 1(a) Number of total tweets and the number of sports tweets 1(b) number of sports tweets by day 
Table 2 Number of total tweets and number of sports tweets by the districts.

\begin{tabular}{|c|c|c|c|c|}
\hline Districts & Tweet & $\begin{array}{c}\text { Tweet } \\
\text { Entropy }\end{array}$ & $\begin{array}{c}\text { Sports } \\
\text { Facility }\end{array}$ & $\begin{array}{l}\text { S. Facility } \\
\text { Entropy }\end{array}$ \\
\hline Adalar & 10 & 0.7729 & 8 & 0.9388 \\
\hline Arnavutkoy & 8 & 0.5873 & 6 & 0.3166 \\
\hline Atasehir & 1062 & 0.8966 & 7 & 0.3151 \\
\hline Avcilar & 91 & 0.8921 & 5 & 0.4709 \\
\hline Bagcilar & 88 & 0.6601 & 5 & 0.9040 \\
\hline Bahcelievler & 105 & 0.5072 & 11 & 0.6510 \\
\hline Bakirkoy & 267 & 0.6389 & 11 & 0.8044 \\
\hline Basaksehir & 176 & 0.8652 & 5 & 0.5822 \\
\hline Bayrampasa & 66 & 0.6490 & 9 & 0.3872 \\
\hline Besiktas & 720 & 0.9381 & 7 & 0.7828 \\
\hline Beykoz & 136 & 0.7703 & 10 & 0.7967 \\
\hline Beylikduzu & 40 & 1.0000 & 2 & 0.8265 \\
\hline Beyoglu & 118 & 0.8932 & 10 & 0.4042 \\
\hline Buyukcekmece & 46 & 0.7287 & 9 & 0.7736 \\
\hline Catalca & 6 & 0.2629 & 6 & 0.0000 \\
\hline Cekmekoy & 49 & 0.6554 & 5 & 0.7186 \\
\hline Esenler & 45 & 0.7218 & 3 & 0.7603 \\
\hline Esenyurt & 97 & 0.8237 & 6 & 0.4387 \\
\hline Eyup & 134 & 0.6453 & 16 & 0.4595 \\
\hline Fatih & 200 & 0.7846 & 11 & 0.5401 \\
\hline Gaziosmanpasa & 33 & 0.5636 & 10 & 0.5019 \\
\hline Gungoren & 76 & 0.4978 & 5 & 0.8404 \\
\hline Kadikoy & 1139 & 0.9417 & 9 & 0.7751 \\
\hline Kagithane & 99 & 0.9602 & 5 & 0.9178 \\
\hline Kartal & 63 & 0.7021 & 10 & 0.7800 \\
\hline Kucukcekmece & 102 & 0.5552 & 12 & 0.5769 \\
\hline Maltepe & 172 & 0.9024 & 4 & 0.4453 \\
\hline Pendik & 89 & 0.6122 & 17 & 0.8184 \\
\hline Sancaktepe & 23 & 0.5623 & 8 & 0.4511 \\
\hline Sariyer & 195 & 0.7900 & 18 & 0.7694 \\
\hline Sile & 6 & 0.6687 & 2 & 0.3810 \\
\hline Silivri & 19 & 0.5107 & 8 & 0.5449 \\
\hline Sisli & 604 & 0.8402 & 6 & 1.0000 \\
\hline Sultanbeyli & 15 & 0.5168 & 5 & 0.6901 \\
\hline Sultangazi & 32 & 0.6218 & 6 & 0.9552 \\
\hline Tuzla & 37 & 0.7204 & 3 & 0.8713 \\
\hline Umraniye & 155 & 0.6241 & 9 & 0.8806 \\
\hline Uskudar & 188 & 0.7741 & 12 & 0.8298 \\
\hline Zeytinburnu & 47 & 0.7561 & 8 & 0.2319 \\
\hline
\end{tabular}

Istanbul Metropolitan area has 309 units for sports facilities allocated to 39 districts of Istanbul city. All the sports facilities within the districts were presented in dot map format in Figure 2 and shown in a clustered column chart in Figure 3. Every dot represents one sports facility in Figure 2. Districts that have the most supply for sports facilities are Eyup, Sariyer, and Pendik. The districts which have the second highest supply class are Bahcelievler, Bakirkoy, Fatih, Kucukcekmece, and Uskudar.

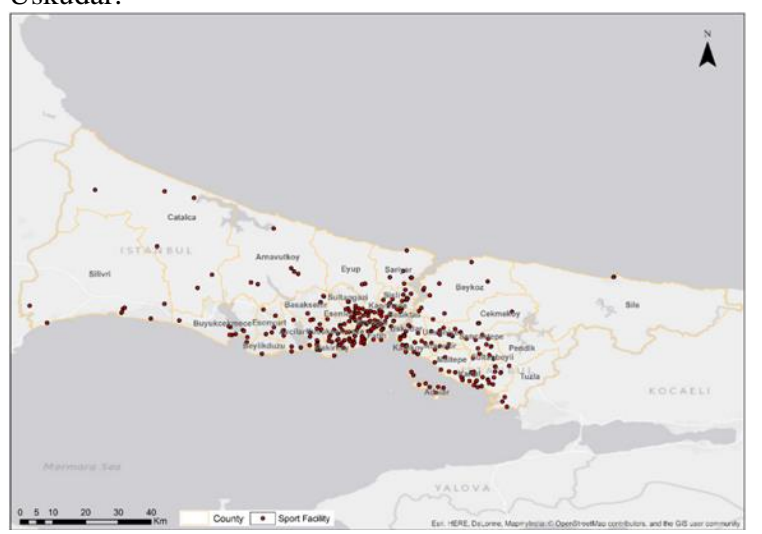

Figure 2 Distribution of sports facilities

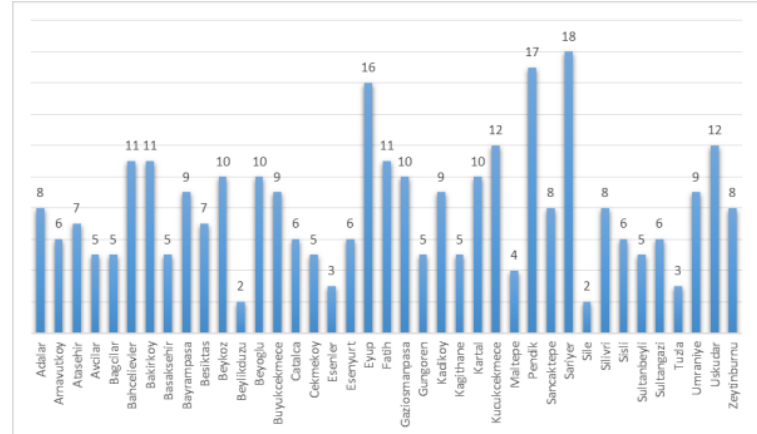

Figure 3 Number of Sports Facilities by Districts

The tweets having texts such as "football", "basketball", "fitness", "swimming," "tennis" etc. were presented in a dot map format in Figure 4 and shown in clustered column chart in Figure 5. Every dot represents a single tweet in Figure 4. The most sports-related tweets are determined within the boundaries of Atasehir, Besiktas, Kadikoy and Sisli districts.

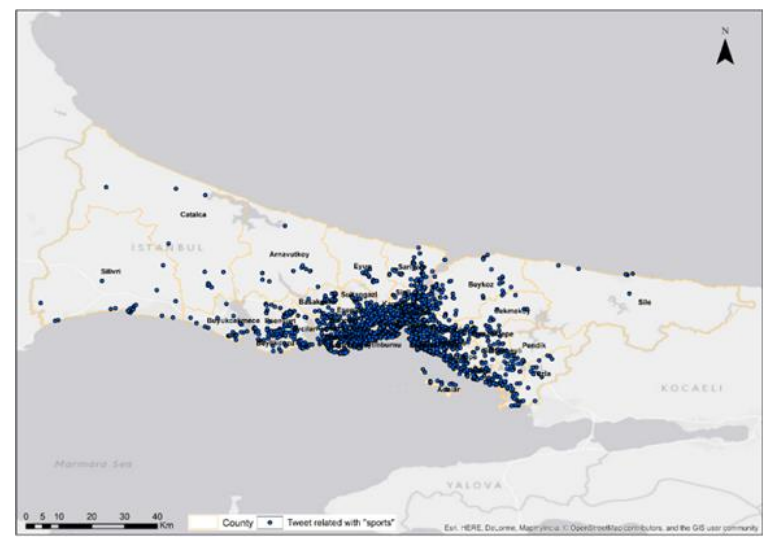

Figure 4 Distribution of tweets.

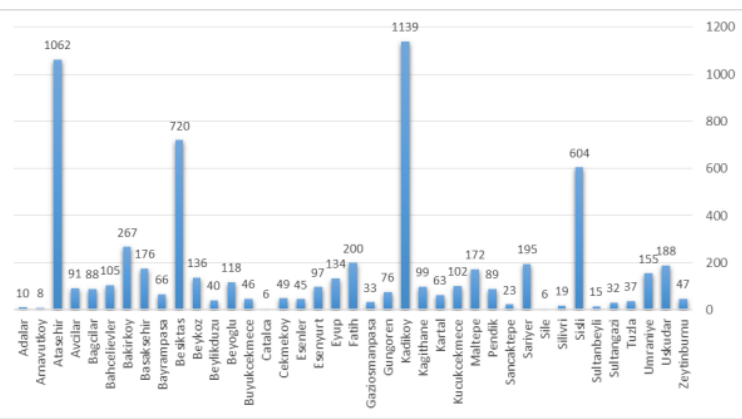

Figure 5 Number of sports related tweets by the districts

Distribution of both sports facilities and people's tweets on sports respectively as supply and demand have been mapped above according to their counts in related districts. However, there is no consideration for the location of the sports facilities and tweets if those are not involved in the same district's boundary even though, those have more capability to supply due to proximity. 
Metric entropy method is useful for considering the impact areas of each sports facilities. The results of entropy within the districts have been spatially joined, then mapped as five natural break classes and presented in choropleth map format with the light to dark tones of red color in Figure 6.

Except for spatial distribution of the tweet demands for the sports facilities, the entropy of the demands for sports determined. This method helped to visualize, which districts require more supply as sports facilities. By considering this, each tweet has its Voronoi area and entropy value without district boundary, the value of total entropy has been calculated for total Voronoi areas including each district and shown in Table 2. Entropy values of tweets related to sports were classified and presented in choropleth map and shown in Figure 7 with light to dark tones of blue color.

Accordingly, in Figure 7, the districts with highest needs to sports facilities are expressed in blue color, which are Atasehir, Avcilar, Besiktas, Beylikduzu, Beyoglu, Basaksehir, Kadikoy, Kagithane, and Maltepe.

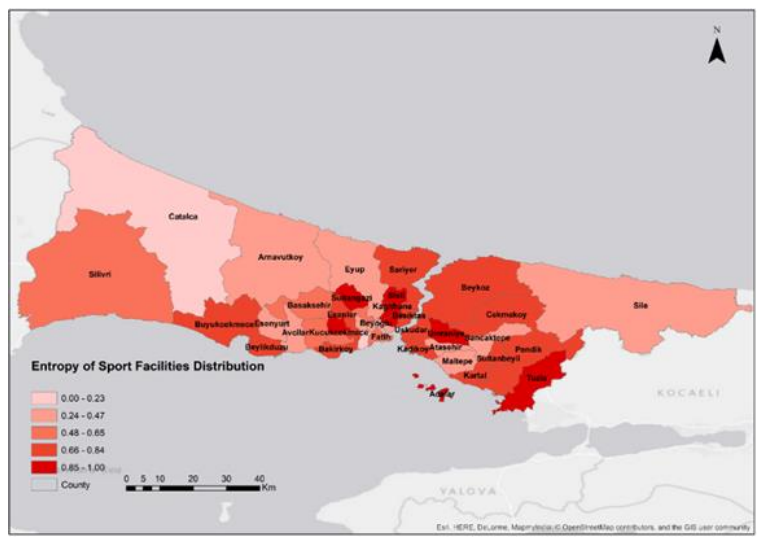

Figure 6 Entropy of sports facilities respect to districts

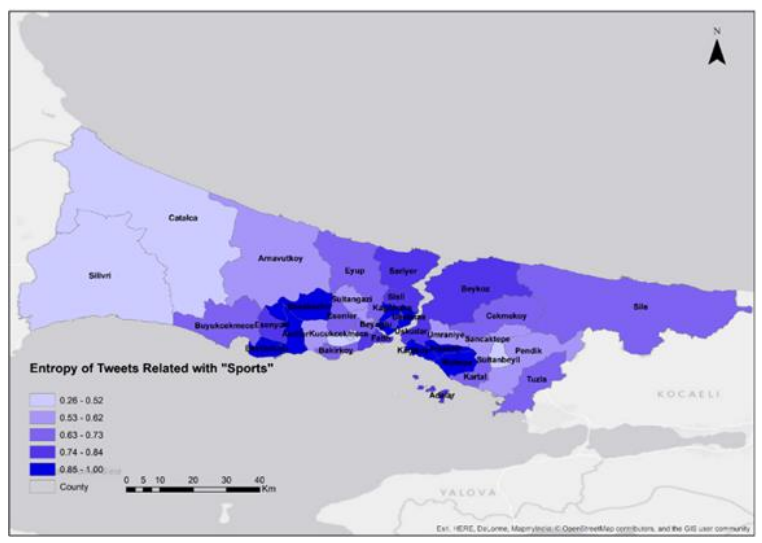

Figure 7 Entropy of tweets related to sports respect to districts of Istanbul.

The results in Figure 6 and Figure 7 show the unbalanced distribution of sports facilities based on demand and supply. In addition to that, Figure 8 shows both entropy values and differences between tweet entropy and sport facility values. Evaluation of all these results is mentioned in "Conclusion and Outlook" section.

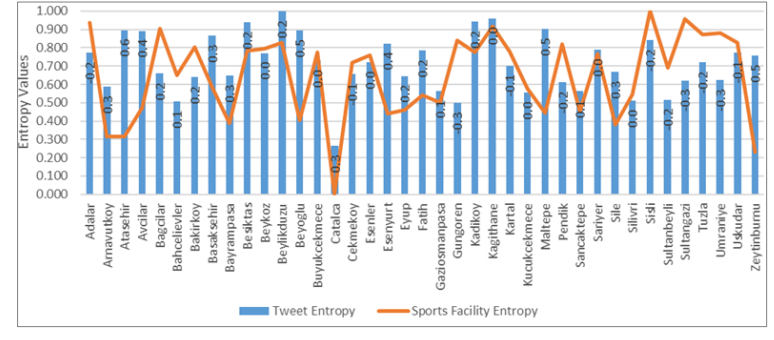

Figure 8 Differences between tweet entropy and sports facility entropy values

\section{RESULTS AND DISCUSSION}

Sports facility distribution in the urban design as an affecting manner of the daily routine may stimulate and change the lifestyle of the related society. Therefore, the design should contribute to and increase the demand for sports in society. As stated in the earlier sections, sports facilities in the urban environment play a significant role in the health of society, as much as on individual health. Sports facility distribution in the urban area has various essential effects to the region like the economy. The example of the UK in 2015 provides an essential outcome for the effects of a sports facility on the country's economy. Inactivity of British society has adverse effects on the economy where low activity has cost National Health Service around £7.4 billion annually (Sport, 2015).

As illustrated in Figure 8, a new result was obtained by calculating the difference between tweet entropy and sports facility entropy values. Thus, tweet entropy columns and sports facility columns overlaid. According to the results of this analysis, it can be interpreted whether the sports facilities are sufficient and whether they are located in significant locations. If a district has a low entropy value of sports facility, existing sports facilities are homogeneously located in that district. Similarly, low tweet entropy values indicate that the tweets for sports facility are homogeneously distributed to the district. When a district has both same grade sports facility and tweet entropy values, sports facilities in the district meet the demands and facilities located on significant locations. On the other hand, if the difference value is negative, locations of tweets are homogeneously distributed in the district meaning the sports facilities demanded from the homogeneously distributed people in the district, but the locations of sports facilities are not distributed homogeneously. So, these sports facilities are located in a narrow part of the district, which is not related to tweet locations, and they are away from the people tweeting.

On the contrary, when the difference value is positive, even if sports facilities are homogeneously distributed, it can be understood that there are not enough people searching for sports facilities in near of these sports facilities. In such a case, locations of the sports facilities are not suitable/significant for the people demands. In summary, it can also be understood that the locations of sports facilities cannot be successfully be determined when the difference is positive or negative. Moreover, increasing the absolute value of the difference is the indication of the disunity between locations of demands and sports facilities. 


\section{CONCLUSION}

In this paper, the importance of sports facilities in an urban area and the needs of an active society have been evaluated and analyzed. The current distribution of sports facilities in Istanbul was evaluated by combining four scientific approaches of urban design, entropy, social media, and geographic information. Moreover, urban design principles and regulations for the sports facilities have been studied and summarized as an element of social infrastructure areas based on spatial planning code of Turkey. Metric entropy method was used as a criterion to compare the location of the sports facilities. This method can be an essential component in estimating the success of a project or site plan including the location of sports facilities in the district. Thus, existing or planned sports facilities can be evaluated by the method, and significant results could be obtained and discussed.

Based on the findings of this study, a different approach for the determination of the locations of sports facilities regarding of the community demands has been introduced. These findings will provide a useful basis for further researches. Metric entropy method can contribute to planning activities for future investment on sports facilities. Additionally, it may lay a foundation for the other metropole cities, where living millions of people are living and maybe an essential criterion for sports activities that will affect thousands of people.

\section{ACKNOWLEDGEMENTS}

The authors would like to thank Istanbul Metropolitan Municipality for providing information for the sports facilities with the locations.

\section{REFERENCES}

Adams, T. (1935). Outline of town and city planning: A review of past efforts and modern aims. Russell Sage Foundation.

Agriculture Organization of the United Nations Interdepartmental Working Group on Land Use Planning. Guidelines for land-use planning. (1993). Food and Agriculture Organization of the United Nations.

Anderson, L.T. (1995). Guidelines for preparing urban plans. Planners Press, American Planning Association

Bale, J. (2002). Sports geography. ISBN 0419252304, Routledge, Taylor \& Francis Group, NY-USA.

Ball, M. (2002). Cultural explanation of regional property markets: A critique. Urban Studies, 39, 1453-1469.

Bjørke, J.T. (1996). Framework for entropy-based map evaluation. Cartography and Geographic Information Systems, 23, 78-95.

Campbell, J., (1999). Harrison S. Professional sports and urban development: A brief review of issues and studies, 21.
Coates, D., \& Humphreys, B. R. (2003). Professional sports facilities, franchises and urban economic development. Public Finance and Management, 3(3), 335-357.

Collins, M. (2014). Sport and social exclusion. ISBN 9780-415-56881-4, Routledge, Taylor \& Francis Group, NYUSA.

Chapin, T. (1999). The political economy of sports facility location: An end-of-the-century review and assessment Marquette Sports Law Review, 10.

Chapin, T.S. (2002). Identifying the real costs and benefits of sports facilities. Citeseer.

Chapin, T.S. (2004). Sports facilities as urban redevelopment catalysts: Baltimore's camden yards and cleveland's gateway. Journal of the American Planning Association, 70, 193-209.

Davies, L.E. (2008). Sport and the local economy: The effects of stadia development on the commercial property market. Local Economy, 23, 31-46.

De Wrachien, D. (2003). Land use planning: a key to sustainable agriculture. In Conservation Agriculture (pp. 471-483). Springer, Dordrecht.

European Commission. (2007). White paper on sport.

Fairbairn, D. (2006). Measuring map complexity. Cartographic Journal 43, 224-238.

Gengec, N. (2015). Geotweet downloader.

Goodchild, M.F. (2007). Citizens as sensors: The world of volunteered geography. GeoJournal, 69, 211-221.

Goodchild, M. (2009). Neogeography and the nature of geographic expertise. Journal of location based services, 3, 82-96.

Gulnerman, A.G.; Karaman, H. (2015). In PPGIS case studies comparison and future questioning, Computational Science and its Applications (ICCSA), $15^{\text {th }}$ International Conference on, IEEE: pp 104-107.

Gulnerman, A.; Gengec, N.; Karaman, H. (2016). Review of public tweets over Turkey within a pre-determined time. ISPRS Annals of the Photogrammetry, Remote Sensing and Spatial Information Sciences, 4, 153.

Iscan F, Ilgaz, A. (2017). Analysis of geographic/urban information system web presentations of local governments in Turkey, International Journal of Engineering and Geosciences, 2 (3), 75-83.

Kozma, G. (2014). The spatial development of sports facilities within the cities: A central European case study. Geosport for Society, Editura universităţii din Oradea, 1, 19-28.

Kozma, G.; Pénzes, J.; Molnár, E. (2016). Spatial development of sports facilities in Hungarian cities of county rank. In Bulletin of Geography. Socio-economic Series, Vol. 31, p 37. 
Kuşçu Ş.Ç., Türk, T., Ödül, H. and Çelik, M.N. (2018). Detection of paragliding fields by GIS, International Journal of Engineering and Geosciences, 3 (3), 119-125.

Lee, Y.; Li, Z.; Li, Y. (2000). Taxonomy of space tessellation. ISPRS Journal of Photogrammetry and Remote Sensing, 55, 139-149.

Li, Z.; Huang, P. (2002). Quantitative measures for spatial information of maps. International Journal of Geographical Information Science, 16, 699-709.

Liebling, T.M.; Pournin, L. (2012). Voronoi diagrams and delaunay triangulations: Ubiquitous siamese twins. Documenta Mathematics, ISMP, 419-431.

Mumford, L. (1938). The culture of cities by Lewis Mumford. Harcourt, Brace and company: New York.

Neumann, J. (1994). The topological information content of a map/an attempt at a rehabilitation of information theory in cartography. Cartographica: The International Journal for Geographic Information and Geovisualization, 31, 26-34.

Ristea, A.; Kurland, J.; Resch, B.; Leitner, M.; Langford, C. (2018). Estimating the spatial distribution of crime events around a football stadium from georeferenced tweets. ISPRS International Journal of Geo-Information, 7,43 .

Sieber, R. (2006). Public participation Geographic Information Systems: A literature review and framework. Annals of the Association of American Geographers, 96, 491-507.

Sukhov, V. (1967). Information capacity of a map entropy. Geodesy and Aerophotography, 10, 212-215.

Sukhov, V. (1970). Application of information theory in generalization of map contents. International Yearbook of Cartography, 10, 41-47.

Sukumar, N., Moran, B., Yu Semenov, A., \& Belikov, V. V. (2001). Natural neighbour Galerkin methods. International journal for numerical methods in engineering, 50(1), 1-27.

Schilling, J.; Linton, L.S. (2005). The public health roots of zoning: In search of active living's legal genealogy. American journal of preventive medicine, 28, 96-104.
Shannon, C.E. (1948). A mathematical theory of communication. Bell System Technical Journal, 27, 623656.

Shannon, C.E.; Weaver, W.; Burks, A.W. (1951). The mathematical theory of communication (review). Philosophical Review, 60.

Shekhar, S. (2015). From GPS and Google Maps to spatial computing.

Sport England. (2015). Active design: Planning for health and wellbeing through sport and physical activity. Public Health England.

Statista. (2016). Number of monthly active Twitter users worldwide from 1st quarter 2010 to 3rd quarter 2015 (in millions).

Tulloch, D.L. (2008). Is VGI participation? From vernal pools to video games. GeoJournal, 72, 161-171.

Thornley, A. (2002). Urban regeneration and sports stadia. European Planning Studies, 10, 813-818.

UN Inter-Agency Task Force on Sport for Development and Peace. (2005). Sport as a tool for development and peace: Towards achieving the United Nations millennium development goals.

United Nations. (2016). The world's cities in 2016: Data booklet.

Van Bottenburg, M.; Rijnen, B.; W.J.H. Mulier Instituut, C.v.S.-W.S.; Sterkenburg, J.C. (2005). Sports participation in the European Union: Trends and differences. Arko Sports Media.

Voronoi, G. (1908). Nouvelles applications des paramètres continus à la théorie des formes quadratiques. Deuxième mémoire. Recherches sur les parallélloèdres primitifs. Journal für die reine und angewandte Mathematik (Crelles Journal), 198-287.

Voronoi, G. (1909). Nouvelles applications des paramètres continus à théorie des formes quadratiques. Journal für die reine und angewandte Mathematik, 67-182.

Watson, D.F.; Philip, G.M. (1984). Triangle based interpolation. Journal of the International Association for Mathematical Geology, 16, 779-795. 